\title{
On the position of La, Lu, Ac and Lr in the periodic table: a perspective
}

\author{
ADITI CHANDRASEKAR ${ }^{\mathrm{a}}$, MEENAKSHI JOSHI $^{\mathrm{b}, \mathrm{c}}$ and TAPAN K GHANTY ${ }^{\mathrm{b}, \mathrm{c}, *}$ (D \\ ${ }^{a}$ Department of Inorganic and Physical Chemistry, Indian Institute of Science, \\ Bangalore 560 012, Karnataka, India \\ ${ }^{\mathrm{b}}$ Theoretical Chemistry Section, Chemistry Group, Bhabha Atomic Research Centre, \\ Mumbai 400 085, Maharashtra, India \\ ${ }^{\mathrm{c}}$ Homi Bhabha National Institute, Training School Complex, Anushakti Nagar, \\ Mumbai 400 094, Maharashtra, India \\ E-mail: tapang@barc.gov.in
}

MS received 30 October 2019; revised 5 November 2019; accepted 6 November 2019; published online 5 December 2019

\begin{abstract}
The periodic table of elements, organised as blocks of elements that contain similar properties, occupies a central role in chemistry. However, the position of some of the elements in the periodic table is a debate that has been ensuing over the past one and a half long centuries. Particularly, the positions of lanthanum (La), lutetium (Lu), actinium (Ac) and lawrencium (Lr) in the periodic table have been quite controversial. Different kinds of studies carried out by various research groups have yet left the fate of these elements undecided as the results of these investigations suggested that these elements could potentially be placed in the d-block, p-block or all four in the f-block. Our recent work looked into this question from a new perspective, involving encapsulation of $\mathrm{La}, \mathrm{Lu}$, Ac and $\mathrm{Lr}$ into Zintl ion clusters, $\mathrm{Pb}_{12}{ }^{2-}$ and $\mathrm{Sn}_{12}^{2-}$. These clusters were chosen as they provide a fitting environment for the determination of structural, thermodynamic and electronic properties of the encapsulated species. Various results that have been evaluated and subsequently analysed (Joshi et al. in Phys. Chem. Chem. Phys. 20:15253-15272, 2018) in order to seek out similarities and differences for making justified conclusions about the placement of all these four elements in the periodic table are the subject matter of this review article.
\end{abstract}

Keywords. Lanthanide; actinide; f-block elements; density functional calculations; periodic table.

\section{Introduction}

One of the most long-lasting questions in the last century to this has been a deceptively trivial one; the positions of lutetium (Lu), lawrencium (Lr), lanthanum (La) and actinium (Ac) in the modern periodic table. As trivial as it may sound, this problem has been the cause of heated scientific debate and the answers to this question provided by various research groups are in the least agreement with each other. Way back in the 1980s Jensen suggested that La and Ac should belong to the f block and $\mathrm{Lu}$ and $\mathrm{Lr}$ in the d block. ${ }^{1}$ Jensen proposed that the right place for $\mathrm{Lu}$, is in the third group of the periodic table below scandium ( $\mathrm{Sc}$ ) and yttrium (Y). The reasons for such a placement were the absence of empty f-orbitals in $\mathrm{Lu}$, along with its similar periodic trends to Sc and $\mathrm{Y}$

*For correspondence in terms of atomic radii, the sum of the first two ionization potentials, the melting point, and electronegativity. Jensen also assigned Lr to group 3 and below Lu solely based on their similar electronic configuration. ${ }^{1,2}$ This arrangement that resulted in fourteen-element rows for the f-block elements i.e., $\mathrm{La}-\mathrm{Yb}$ and Ac-No is the version adopted by Wikipedia. Subsequent calculations incorporating the relativistic effect, revealed the ground state of $\mathrm{Lr}$ to be $[R n] 5 f^{14} 7 s^{2} 7 p^{1}$ instead of $[R n] 5 f^{14} 6 d^{1} 7 s^{2} .^{3-5}$ On this basis, in stark opposition to Jensen, Lavelle proposed that the La and Ac be placed in the d block while $\mathrm{Lu}$ and Lr must be in the f block. ${ }^{6}$ In 2008, Lavelle claimed that $\mathrm{Lr}$ and $\mathrm{Lu}$ must not be placed in the $\mathrm{d}$ block, but rather that $\mathrm{La}\left([\mathrm{Xe}] 5 \mathrm{~d}^{1} 6 \mathrm{~s}^{2}\right)$ and $\operatorname{Ac}\left([\operatorname{Rn}] 6 \mathrm{~d}^{1} 7 \mathrm{~s}^{2}\right)$ be placed in the $\mathrm{d}$ block owing to their last electron being in a $d$ orbital. Lavelle, hence maintained the view that $\mathrm{Lu}$ and $\mathrm{Lr}$ should remain in the $\mathrm{f}$ block $^{6-8}$ which would still consist of fourteen- 
element rows, Ce-Lu and Th-Lr. The suggestion of Lavelle has been accepted by the Royal Society of Chemistry as well as the American Chemical Society. In addition to these conflicting views with their justifications from both sides, a third proposition emerged in as recently as 2016 from Pyykkö and coworkers ${ }^{9}$ who concluded that all the elements $\mathrm{La}-\mathrm{Lu}$ and $\mathrm{Ac}-\mathrm{Lr}$ are best fitted in 15-element rows in the $\mathrm{f}$ block consisting of lanthanides and actinides, respectively. The first ionization potential of $\mathrm{Lr}$ has been experimentally and theoretically calculated $(4.96 \mathrm{eV})$ and found to be of an exceptionally low value considering the large number of protons in its nucleus. ${ }^{10}$ However, this leads one to the importance of the relativistic effects, particularly while considering the heavy elements. ${ }^{10}$ Pyykkö et al., in 2016, employed the relativistic electronic configuration of $\operatorname{Lr}\left([R n] 5 f^{14} 7 s^{2} 7 p^{1}\right)$, to investigate the effect of the ground state configuration of $\mathrm{Lr}$ on its chemical behaviour. They concluded that both $\mathrm{Lr}$ and $\mathrm{Lu}$ show the same chemical behaviour though their ground state configurations vary. Nevertheless, Pyykkö et al., ${ }^{9}$ showed that $\mathrm{Tl}$ and $\mathrm{Lr}$ have different properties, despite them both possessing similar ground state $\mathrm{np}^{1}$ configurations. In view of their results, Pyykko et al., recommended the placement of all lanthanides ( $\mathrm{La}-\mathrm{Lu})$ and actinides $(\mathrm{Ac}-\mathrm{Lr})$ in the $\mathrm{f}$ block $^{9}$ which will then consist of 15 elements with configurations from $\mathrm{f}^{0}$ to $\mathrm{f}^{14}$ instead of the conventional 14-element f-block. This scheme has been adopted in the modern periodic table as well as by IUPAC. ${ }^{11}$ In effect, these controversies have led to a lack of clarity about the position of $\mathrm{Lr}, \mathrm{Lu}, \mathrm{La}$ and Ac in the periodic table, and this issue remains unresolved till date. In our recent work, ${ }^{12}$ this issue has been addressed by employing encapsulated $\mathrm{M} @ \mathrm{~Pb}_{12}{ }^{2-}$ and $\mathrm{M} @ \mathrm{Sn}_{12}^{2-}$ clusters $\left(\mathrm{M}=\mathrm{Lr}^{\mathrm{n}}, \mathrm{Lu}^{\mathrm{n}}\right.$, or $\mathrm{La}^{3+}, \mathrm{Ac}^{3+}$ where $\left.\mathrm{n}=0,1,2,3\right)$ as model systems to provide in-depth insights into this long-drawn controversy. Thus, structural, thermodynamic and electronic properties of these clusters were studied using density functional theory (DFT) in order to seek out their similarities and differences in a manner such that conclusions can be drawn about the placement of these elements in the periodic table. ${ }^{12}$ The present article is a brief perspective based on these results.

\section{Computational methods}

All the DFT calculations have been carried out ${ }^{12}$ using the TURBOMOLE- $6.6^{13}$ and ADF 2016 $6^{14,15}$ programs. Optimizations have been performed using the
Perdew-Burke-Ernzerhof (PBE) functional ${ }^{16}$ in conjunction with the def-TZVP basis set which has been used along with a relativistic effective core potential (RECP) for all the heavier elements viz., Pb (ECP 78), Sn (ECP 46), Ac (ECP 60), Lr (ECP 60) and Lu (ECP 28). ${ }^{17-23}$ For La, the def2-TZVP basis set has been used during the calculations along with ECP 46. Further details are given in Ref ${ }^{12}$.

\section{Choosing encapsulated clusters of tin and lead as model systems}

Following the discovery of fullerene $\left(\mathrm{C}_{60}\right.$ cluster), new avenues opened in the area of cluster research. ${ }^{24-29}$ Its unique truncated icosahedral structure possessing a large diameter of $7 \AA$ enables the $\mathrm{C}_{60}$ cluster to accommodate a wide selection of atoms or ions within it. This leads to the creation of "doped clusters" with applications in different areas of science including biology, nanotechnology and medicine. ${ }^{24-29}$ Such clusters when doped with atoms or ions have been known to display useful electronic, magnetic and chemical properties including catalytic activity. ${ }^{30-32}$ Apart from clusters of carbon, other elements have since evolved in the emerging field of cluster research. Several of these have been theoretically been conceived and a subset of these has been experimentally synthesised. Twelve atom clusters of tin and lead known as "stannaspherene" $\left(\mathrm{Sn}_{12}^{2-}\right)^{33}$ and "plumbaspherene" $\left(\mathrm{Pb}_{12}{ }^{2-}\right),{ }^{34}$ respectively were experimentally realised in 2006 by Cui et al. Interestingly, both the $\mathrm{Pb}_{12}{ }^{2-}$ and $\mathrm{Sn}_{12}^{2-}$ clusters are similar to fullerene in that they have spherical pi bonding as well as an empty cage with relatively large diameters of $6.3 \AA$ and $6.1 \AA$, respectively, which are only marginally shorter than the internal diameter of the $\mathrm{C}_{60}$ cage $(7 \AA)$. Thus, a variety of transition metal and lanthanide encapsulated clusters of $\mathrm{Pb}_{12}{ }^{2-}$ and $\mathrm{Sn}_{12}^{2-}$ have been investigated experimentally. ${ }^{35-42}$ Thus, there is a plethora of captivating metal atom or ion encapsulated $\mathrm{Si}_{\mathrm{n}}^{-}, \mathrm{Ge}_{\mathrm{n}}^{-}$, $\mathrm{Sn}_{\mathrm{n}}^{-}$and $\mathrm{Pb}_{12}{ }^{2-}$ clusters that have been experimentally and theoretically examined. ${ }^{43-58} \mathrm{~A}$ few examples include kinetically stable noble gas atom or dimer $\left(\mathrm{H}_{2}\right.$ and $\mathrm{He}_{2}$ ) encapsulated $\mathrm{Pb}_{12}{ }^{2-}$ and $\mathrm{Sn}_{12}^{2-}$ clusters which have been predicted by our group. ${ }^{59}$ Addressing the point of stability, it has additionally been shown that encapsulated $\mathrm{Pb}_{12}{ }^{2-}$ and $\mathrm{Sn}_{12}^{2-}$ clusters preserved their structural integrity even at high temperatures of $700 \mathrm{~K}^{59}$ Delving further, considering their similar cage sizes, the possibility of having an $\mathrm{Lr} @ \mathrm{C}_{60}$ clus$\operatorname{ter}^{60}$ makes the prediction of $\mathrm{Lr}$ or $\mathrm{Lu}$ encapsulated $\mathrm{Pb}_{12}{ }^{2-}$ and $\mathrm{Sn}_{12}^{2-}$ clusters realisable. 


\section{Structure and binding energy}

We have extensively investigated $\mathrm{M}_{0} \mathrm{~Pb}_{12}{ }^{2-}$ and $\mathrm{M} @ \mathrm{Sn}_{12}^{2-}$ clusters $\left(\mathrm{M}=\mathrm{Lr}^{\mathrm{n}+}, \mathrm{Lu}^{\mathrm{n}+}, \mathrm{La}^{3+}\right.$ and $\mathrm{Ac}^{3+}$ where $\mathrm{n}=0,1,2,3)$ using density functional theory (DFT). With the sole objective to determine the position of these four elements in the periodic table, the similarities or dissimilarities in their electronic, structural and thermodynamic properties have been extensively discussed. ${ }^{12}$ The synthesis of $\mathrm{M} @ \mathrm{~Pb}_{12}{ }^{2-}$ and $\mathrm{M} @ \mathrm{Sn}_{12}^{2-}$ clusters could well be made possible through photoelectron spectroscopy, as $\mathrm{Lu} @ \mathrm{Ge}_{\mathrm{n}}^{-44}$ and $\mathrm{M} @ \mathrm{Si}_{\mathrm{n}}^{-}(\mathrm{n}=6-20)^{43}$ clusters have already been prepared experimentally. We have mainly focused on the metal encapsulated $\mathrm{Pb}_{12}{ }^{2-}$ and $\mathrm{Sn}_{12}^{2-}$ clusters in which the metal ions exist in their most stable oxidation state of +3 viz., $\mathrm{Lu}^{3+}, \mathrm{Lr}^{3+}, \mathrm{La}^{3+}$ and $\mathrm{Ac}^{3+}$. However, in order to make an effective comparison with the +3 state, other charged $\mathrm{M}_{0} \mathrm{~Pb}_{12}{ }^{2-}$ and $\mathrm{M} @ \mathrm{Sn}_{12}^{2-}\left(\mathrm{M}=\mathrm{Lr}^{\mathrm{n}+}, \mathrm{Lu}^{\mathrm{n}+}, \mathrm{n}=0,1,2\right)$ clusters have also been examined to the same extent with respect to structural, energetic, and electronic properties. Furthermore, in each case, the thermodynamic property of the binding energy during the encapsulation process has also been analyzed. Interestingly, all $\mathrm{M} @ \mathrm{~Pb}_{12}{ }^{+}$ and $\mathrm{M} @ \mathrm{Sn}_{12}^{+}(\mathrm{M}=\mathrm{Lr}$ and $\mathrm{Lu})$ clusters were found to be stable 18-bonding-electron systems with shell closing.

First, we have investigated the icosahedral geometry for the bare $\mathrm{Pb}_{12}{ }^{2-}$ and $\mathrm{Sn}_{12}^{2-}$ cages which is the global minimum structure of the bare $\mathrm{Pb}_{12}{ }^{2-}$ and $\mathrm{Sn}_{12}^{2-}$ cages. ${ }^{33,34,61}$ Metal encapsulated various 13-atom clusters with closed-shell configurations have been shown experimentally and theoretically to possess an icosahedral structure as their ground state geometry. ${ }^{30,38,39,41,42,62,63}$ The addition or removal of electrons to this closed-shell configuration of the clusters reduces the symmetry. ${ }^{53,64} \mathrm{We}$ have predicted various structures for the metal-doped clusters in different oxidation states. The optimized minimum energy geometries of the encapsulated clusters $\mathrm{M} @ \mathrm{~Pb}_{12}{ }^{2-}$ and $\mathrm{M} @ \mathrm{Sn}_{12}^{2-}\left(\mathrm{M}=\mathrm{Lr}^{\mathrm{n}+}, \mathrm{Lu}^{\mathrm{n}+} \mathrm{n}=0,1,2,3\right)$ are shown in Figure 1 and their relative energies with respect to the most stable geometry in each oxidation state of $\mathrm{Lr}$ and $\mathrm{Lu}$ are listed (Table 1). The binding energy is a guiding parameter indicating the stability of the clusters. All the binding energies of $\mathrm{Lr}$ and $\mathrm{Lu}$ encapsulated $\mathrm{Pb}_{12}{ }^{2-}$ and $\mathrm{Sn}_{12}^{2-}$ clusters are negative (Table 2) indicating that they are thermodynamically stable. In every case, a decrease in the charge on the

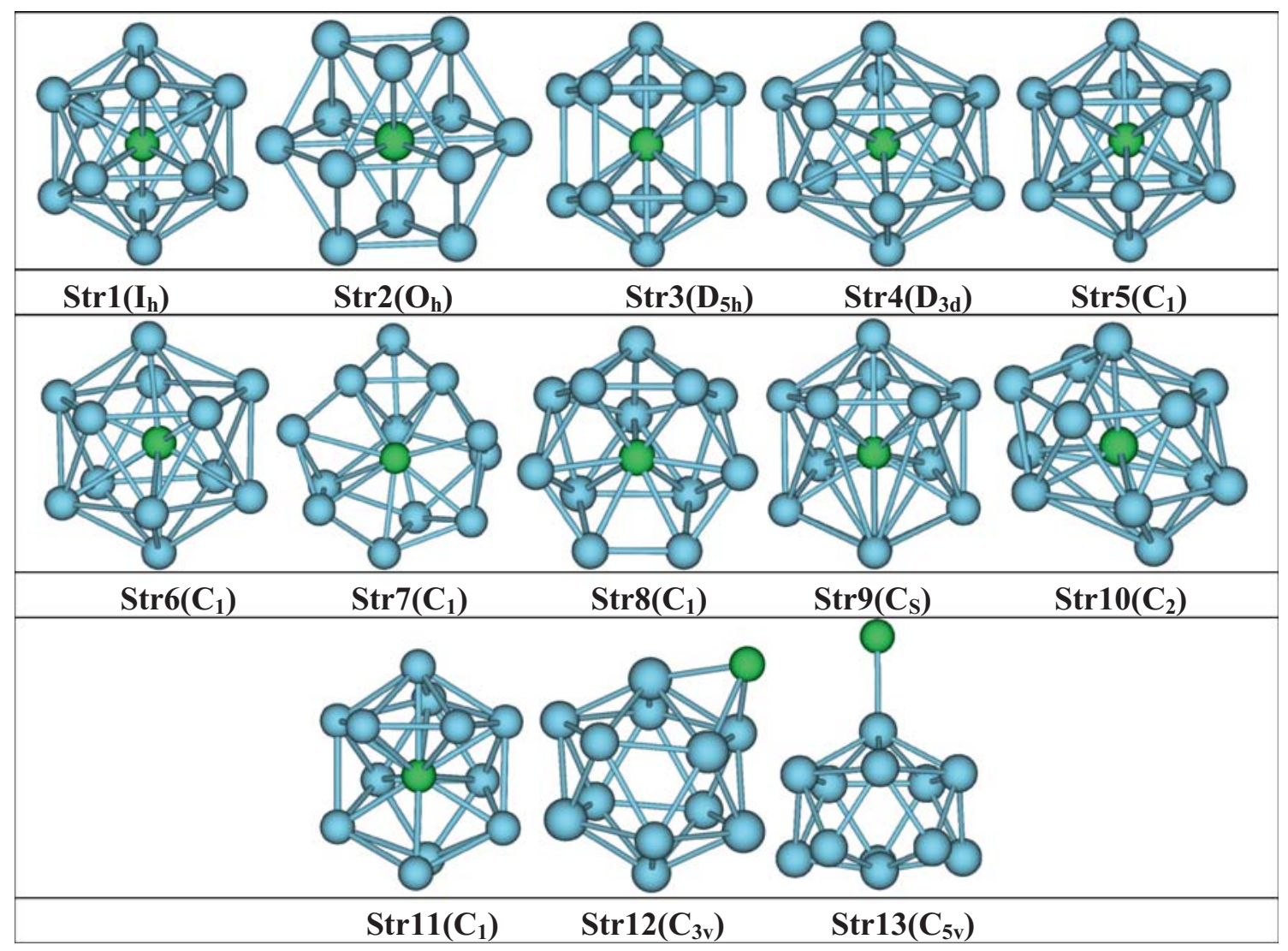

Figure 1. Optimized structures of $\mathrm{M} @ \mathrm{~Pb}_{12}{ }^{2-}\left(\mathrm{M}=\mathrm{Lr}^{\mathrm{n}+}, \mathrm{Lu}^{\mathrm{n}+}\right.$ and $\left.\mathrm{n}=0,1,2,3\right)$ clusters (Reproduced from Ref. ${ }^{12}$ with permission from the Royal Society of Chemistry). 
Table 1. Relative Energy ( $\mathrm{RE}$ in $\mathrm{eV})$ of various isomers of $\mathrm{M} @ \mathrm{E}_{12}{ }^{2-}\left(\mathrm{M}=\mathrm{Lr}^{\mathrm{n}+}, \mathrm{Lu}^{\mathrm{n}+}, \mathrm{E}=\right.$ $\mathrm{Pb}, \mathrm{Sn}$ and $\mathrm{n}=0,1,2,3)$ Clusters. $^{\mathrm{a}, \mathrm{b}}$

\begin{tabular}{|c|c|c|c|c|c|}
\hline \multirow[b]{2}{*}{ Geometry } & \multicolumn{2}{|c|}{$\mathrm{RE}$} & \multirow[b]{2}{*}{ Geometry } & \multicolumn{2}{|c|}{$\mathrm{RE}$} \\
\hline & $\mathrm{Lr}^{\mathrm{n}} @ \mathrm{~Pb}_{12}^{2-}$ & $\mathrm{Lu}^{\mathrm{n}} @ \mathrm{~Pb}_{12}^{2-}$ & & $\mathrm{Lr}^{\mathrm{n}} @ \mathrm{Sn}_{12}^{2-}$ & $\mathrm{Lu}^{\mathrm{n}} @ \mathrm{Sn}_{12}^{2-}$ \\
\hline \multicolumn{6}{|l|}{$\mathrm{M} @ \mathrm{E}_{12}{ }^{+}$} \\
\hline $\operatorname{Str} 1\left(\mathrm{I}_{\mathrm{h}}\right)$ & 0.000 & 0.000 & $\operatorname{Str} 1\left(I_{h}\right)$ & 0.000 & 0.000 \\
\hline $\mathrm{Str} 2\left(\mathrm{O}_{\mathrm{h}}\right)$ & $2.127^{\mathrm{c}}$ & $2.225^{\mathrm{c}}$ & $\operatorname{Str} 2\left(\mathrm{O}_{\mathrm{h}}\right)$ & $1.830^{\mathrm{c}}$ & $1.938^{\mathrm{c}}$ \\
\hline $\operatorname{Str} 3\left(D_{5 h}\right)$ & $2.755^{\mathrm{c}}$ & $2.861^{\mathrm{c}}$ & $\operatorname{Str} 3\left(D_{5 h}\right)$ & $2.309^{c}$ & $2.397^{\mathrm{c}}$ \\
\hline $\operatorname{Str} 12\left(\mathrm{C}_{3 \mathrm{v}}\right)(\mathrm{exo})$ & 1.331 & 2.096 & $\operatorname{Str} 12\left(\mathrm{C}_{3 \mathrm{v}}\right)(\mathrm{exo})$ & 0.516 & 1.331 \\
\hline $\operatorname{Str} 13\left(\mathrm{C}_{5 \mathrm{v}}\right)(\mathrm{exo})$ & $2.060^{\mathrm{c}}$ & $3.550^{\mathrm{c}}$ & $\operatorname{Str} 13\left(\mathrm{C}_{5 \mathrm{v}}\right)(\mathrm{exo})$ & $1.161^{\mathrm{c}}$ & $2.765^{\mathrm{c}}$ \\
\hline \multicolumn{6}{|l|}{$\mathrm{M} @ \mathrm{E}_{12}$} \\
\hline $\operatorname{Str} 4\left(D_{3 d}\right)$ & 0.000 & 0.000 & $\operatorname{Str} 4\left(D_{3 d}\right)$ & 0.000 & 0.011 \\
\hline $\operatorname{Str} 5\left(C_{1}\right)$ & 0.011 & 0.010 & $\operatorname{Str} 6\left(C_{1}\right)$ & 0.042 & 0.000 \\
\hline $\operatorname{Str6}\left(C_{1}\right)$ & 0.015 & 0.009 & $\operatorname{Str} 7\left(C_{1}\right)$ & 0.556 & 0.967 \\
\hline $\operatorname{Str} 7\left(C_{1}\right)$ & 1.824 & 1.607 & & & \\
\hline \multicolumn{6}{|l|}{$\mathrm{M} @ \mathrm{E}_{12}^{-}$} \\
\hline $\operatorname{Str} 8\left(C_{1}\right)$ & 0.000 & 0.000 & $\operatorname{Str} 8\left(C_{1}\right)$ & 0.000 & 0.000 \\
\hline $\operatorname{Str} 9\left(C_{\mathrm{s}}\right)$ & 0.222 & 0.185 & $\operatorname{Str} 6\left(C_{1}\right)$ & 0.724 & 0.546 \\
\hline $\operatorname{Str} 4\left(D_{3 d}\right)$ & 0.384 & 0.184 & $\operatorname{Str} 12\left(C_{1}\right)$ & 0.422 & 0.393 \\
\hline $\operatorname{Str} 7\left(C_{1}\right)$ & 1.216 & 1.329 & $\operatorname{Str} 7\left(C_{1}\right)$ & 1.173 & 0.781 \\
\hline \multicolumn{6}{|l|}{$\mathrm{M} @ \mathrm{E}_{12}{ }^{2-}$} \\
\hline $\operatorname{Str} 10\left(C_{2}\right)$ & 0.000 & 0.000 & $\operatorname{Str} 8\left(C_{1}\right)$ & 0.000 & 0.000 \\
\hline $\operatorname{Str} 8\left(C_{1}\right)$ & 0.009 & 0.008 & $\operatorname{Str} 10\left(C_{2}\right)$ & 0.142 & 0.202 \\
\hline $\operatorname{Str} 7\left(C_{1}\right)$ & 1.214 & 1.318 & $\operatorname{Str} 7\left(C_{1}\right)$ & 1.031 & 0.861 \\
\hline
\end{tabular}

${ }^{a}$ Symmetry of each isomer is given in the parenthesis.

${ }^{\mathrm{b}}$ All results are taken from Ref. ${ }^{12}$ with permission from the Royal Society of Chemistry.

${ }^{\mathrm{c}}$ Clusters are associated with imaginary frequencies.

Table 2. Binding Energy $\left(\mathrm{BE}\right.$, in eV) of $\mathrm{M} @ \mathrm{E}_{12}{ }^{2-}\left(\mathrm{M}=\mathrm{Lr}^{\mathrm{n}+}, \mathrm{Lu}^{\mathrm{n}+}, \mathrm{La}^{3+}, \mathrm{Ac}^{3+}, \mathrm{E}=\mathrm{Pb}, \mathrm{Sn}\right.$ and $\mathrm{n}=0,1,2,3)$ Clusters. $^{\mathrm{a}}$

\begin{tabular}{|c|c|c|c|c|c|}
\hline $\mathrm{M} @ \mathrm{~Pb}_{12}{ }^{2-}$ & Geometry & $\mathrm{BE}$ & $\mathrm{M} @ \mathrm{Sn}_{12}^{2-}$ & Geometry & $\mathrm{BE}$ \\
\hline $\mathrm{Lu} @ \mathrm{~Pb}_{12}{ }^{+}$ & $\operatorname{Str} 1\left(I_{h}\right)$ & -37.90 & Lu@Sn ${ }_{12}^{+}$ & $\operatorname{Str} 1\left(\mathrm{I}_{\mathrm{h}}\right)$ & -37.03 \\
\hline $\mathrm{Lr} @ \mathrm{~Pb}_{12}{ }^{+}$ & $\operatorname{Str} 1\left(I_{h}\right)$ & -37.19 & $\mathrm{Lr} @ \mathrm{Sn}_{12}^{+}$ & $\operatorname{Str} 1\left(\mathrm{I}_{\mathrm{h}}\right)$ & -36.23 \\
\hline${ }^{\mathrm{b}} \mathrm{La} @ \mathrm{~Pb}_{12}+$ & $\operatorname{Str} 1\left(I_{h}\right)$ & -31.36 & ${ }^{\mathrm{b}, \mathrm{c}} \mathrm{La} @ \mathrm{Sn}_{12}^{+}$ & $\operatorname{Str} 1\left(I_{h}\right)$ & -30.04 \\
\hline 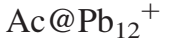 & $\operatorname{Str} 1\left(I_{h}\right)$ & -28.88 & ${ }^{\mathrm{c}} \mathrm{Ac} @ \mathrm{Sn}_{12}^{+}$ & $\operatorname{Str} 1\left(\mathrm{I}_{\mathrm{h}}\right)$ & -27.47 \\
\hline $\mathrm{Lu} @ \mathrm{~Pb}_{12}$ & $\operatorname{Str} 4\left(D_{3 d}\right)$ & -21.61 & Lu@Sn 12 & $\operatorname{Str6}\left(C_{1}\right)$ & -21.16 \\
\hline $\mathrm{Lr} @ \mathrm{~Pb}_{12}$ & $\operatorname{Str} 4\left(D_{3 d}\right)$ & -20.03 & $\mathrm{Lr} @ \mathrm{Sn}_{12}$ & $\operatorname{Str} 4\left(D_{3 d}\right)$ & -19.57 \\
\hline $\mathrm{Lu} @ \mathrm{~Pb}_{12}{ }^{-}$ & $\operatorname{Str} 8\left(C_{1}\right)$ & -9.84 & $\mathrm{Lu} @ \mathrm{Sn}_{12}^{-}$ & $\operatorname{Str} 8\left(C_{1}\right)$ & -10.21 \\
\hline $\mathrm{Lr} @ \mathrm{~Pb}_{12}{ }^{-}$ & $\operatorname{Str} 8\left(C_{1}\right)$ & -8.00 & $\mathrm{Lr} @ \mathrm{Sn}_{12}^{-}$ & $\operatorname{Str} 8\left(C_{1}\right)$ & -8.30 \\
\hline $\mathrm{Lu} @ \mathrm{~Pb}_{12}{ }^{2-}$ & $\operatorname{Str} 10\left(C_{2}\right)$ & -3.67 & $\mathrm{Lu} @ \mathrm{Sn}_{12}^{2-}$ & $\operatorname{Str} 8\left(C_{1}\right)$ & -4.32 \\
\hline $\mathrm{Lr} @ \mathrm{~Pb}_{12}{ }^{2-}$ & $\operatorname{Str} 10\left(\mathrm{C}_{2}\right)$ & -2.79 & $\operatorname{Lr} @ \mathrm{Sn}_{12}^{2-}$ & $\operatorname{Str} 8\left(C_{1}\right)$ & -3.37 \\
\hline
\end{tabular}

${ }^{a}$ All results are taken from Ref. ${ }^{12}$ with permission from the Royal Society of Chemistry.

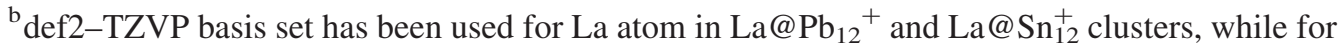
remaining atoms def-TZVP basis set is used.

${ }^{\mathrm{c}}$ Clusters are associated with imaginary frequencies.

encapsulated atom or ion is accompanied by a decrease in binding energy (Table 2). Hence, the greater the positive charge on the encapsulated metal ion, the higher is the interaction between the cage and the encapsulated atom (ion). $\mathrm{Lr}^{\mathrm{n}+}$ encapsulated clusters in their different oxidation states $(\mathrm{n}=0,1,2,3)$ are associated with binding energies very similar to those of $\mathrm{Lu}^{\mathrm{n}+}$ encapsulated clusters in the corresponding oxidation states in spite of the size difference between $\mathrm{Lr}$ and $\mathrm{Lu}$. On comparing these energies with La and Ac clusters, ${ }^{12}$ their binding energy is observed to be relatively smaller than $\mathrm{Lr}$ and $\mathrm{Lu}$ encapsulated 
clusters (Table 2). The larger size of $\mathrm{La}$ and $\mathrm{Ac}$ reduces the stability of the system both in terms of bond length as well as accommodation in the cage.

\section{Density of states and molecular orbital order}

The density of states (DOS) plots for bare $\mathrm{Pb}_{12}{ }^{2-}$ clusters are compared with those of $\mathrm{M} @ \mathrm{~Pb}_{12}{ }^{+}(\mathrm{M}=\mathrm{Lr}$ and Lu) clusters (Figure 2(a)). Intense bands, which correspond to valence $6 \mathrm{~s}, 6 \mathrm{p}$ and $5 \mathrm{~s}, 5 \mathrm{p}$ orbitals are observed for both the bare and encapsulated clusters. However, the DOS of the corresponding peaks for the encapsulated clusters are slightly red-shifted compared to the bare $\mathrm{Pb}_{12}{ }^{2-}$ cluster. However, our purpose is to draw comparisons between the encapsulated clusters and the $\mathrm{Lu}^{3+}$ and $\mathrm{Lr}^{3+}$ ion encapsulated $\mathrm{Pb}_{12}{ }^{2-}$ clusters show almost similar energy shifts. A very similar density of states behaviour is shown by $\mathrm{Lu}^{3+}$ and $\mathrm{Lr}^{3+}$ ion encapsulated $\mathrm{Pb}_{12}{ }^{2-}$ clusters.

Molecular orbital (MO) energy level diagrams of $\mathrm{Lu}^{3+}$ and $\mathrm{Lr}^{3+}$ ion encapsulated $\mathrm{Pb}_{12}{ }^{2-}$ clusters (Figure 2(b)) show fairly large HOMO-LUMO energy gaps for $\mathrm{M} @ \mathrm{~Pb}_{12}{ }^{+}$clusters confirming their chemical stability in addition to the binding energies discussed above. Compared to the $\mathrm{M} @ \mathrm{~Pb}_{12}{ }^{+}$clusters a smaller HOMO-LUMO energy gap is observed for $\mathrm{M} @ \mathrm{Sn}_{12}^{+}$ clusters (Figure 3 ). The smaller size of the $\mathrm{Sn}_{12}^{2-}$ cage marginally de-stabilises the encapsulated cluster in comparison to the corresponding $\mathrm{Pb}_{12}{ }^{2-}$ cluster systems. Clusters in which the encapsulated $\mathrm{Lr}$ and $\mathrm{Lu}$ $\left(\mathrm{Lr}^{\mathrm{n}+}, \mathrm{Lu}^{\mathrm{n}+}\right.$ and $\left.\mathrm{n}=0,1,2\right)$ have positive charges less than +3 have lower HOMO-LUMO gaps. The

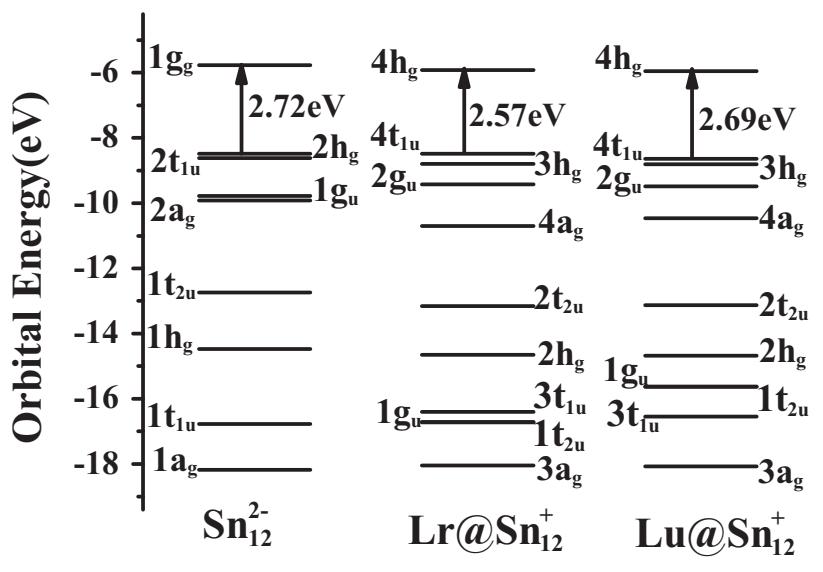

Figure 3. Molecular energy level diagram of bare $\mathrm{Sn}_{12}^{2-}$ and $\mathrm{Lr}^{3+}$ and $\mathrm{Lu}^{3+}$ encapsulated cluster. (Reproduced from Ref. $^{12}$ with permission from the Royal Society of Chemistry).

HOMO-LUMO energy gaps of $\mathrm{Lu}^{3+}$ and $\mathrm{Lr}^{3+}$ encapsulated $\mathrm{Pb}_{12}{ }^{2-}$ and $\mathrm{Sn}_{12}^{2-}$ clusters are relatively higher than those for $\mathrm{La}^{3+}$ and $\mathrm{Ac}^{3+}$ encapsulated clusters. Thus, the more negative binding energies of the $\mathrm{Lu}^{3+}$ and $\mathrm{Lr}^{3+}$ encapsulated $\mathrm{Pb}_{12}{ }^{2-}$ and $\mathrm{Sn}_{12}^{2-}$ clusters combined with the higher value of the HOMO-LUMO confirms the relatively higher stability of the $\mathrm{Lu}^{3+}$ and $\mathrm{Lr}^{3+}$ encapsulated clusters.

\section{Electron counting rules and the stability of encapsulated clusters}

The 18-electron rule ${ }^{65,66}$ has been extensively employed in order to explain the stability of several systems; particularly transition metal complexes. ${ }^{67,68}$

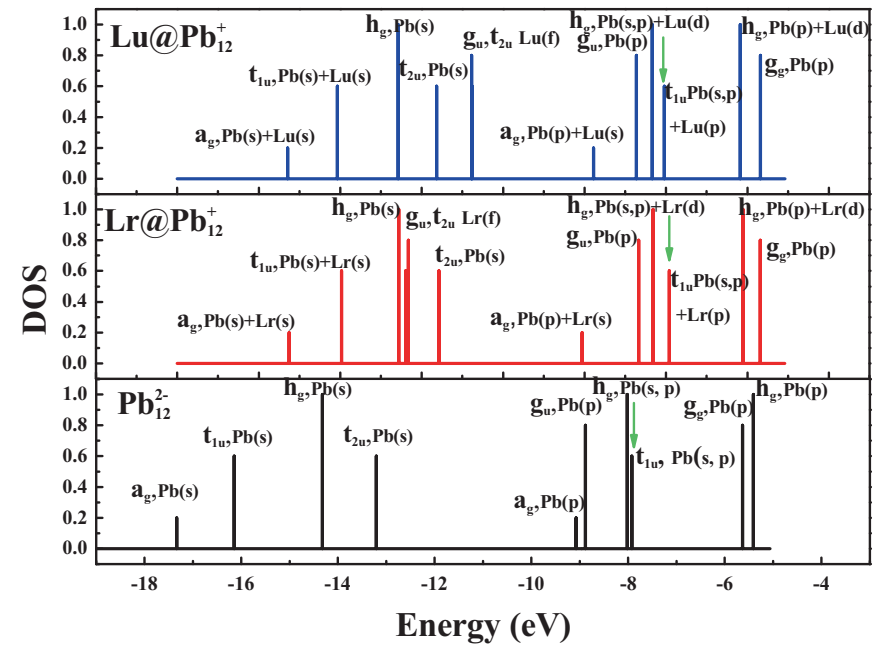

(a)

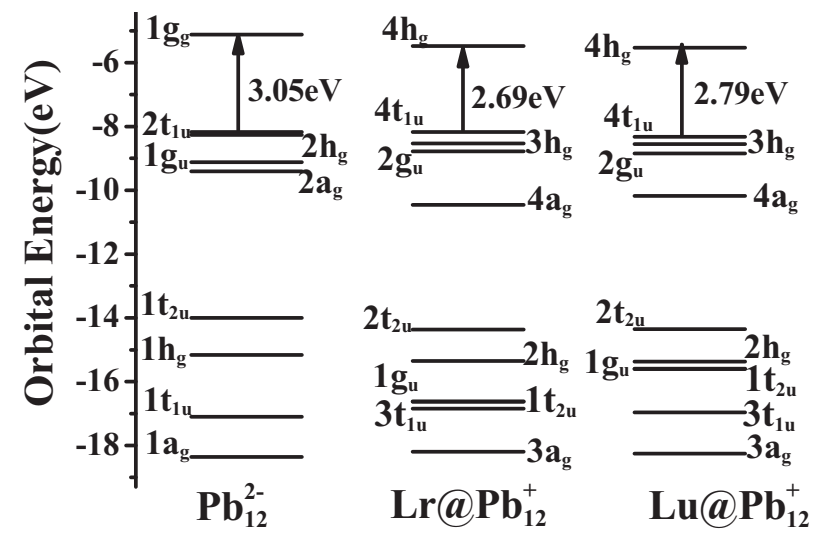

(b)

Figure 2. (a) The variation of density of states (DOS) and (b) Molecular energy level diagram of bare $\mathrm{Pb}_{12}{ }^{2-}$ and $\mathrm{Lr}^{3+}$ and $\mathrm{Lu}^{3+}$ encapsulated cluster. The vertical green arrow is pointing toward HOMO. (Reproduced from Ref. ${ }^{12}$ with permission from the Royal Society of Chemistry). 
Beyond this purview, in the recent past the 18-electron counting rule has succeeded in explaining the stability of clusters such as W@ $\mathrm{Au}_{12}$ and $\mathrm{Sg} @ \mathrm{Au}_{12} .{ }^{62,63,69,70}$ However, for early lanthanide and actinide encapsulated clusters, the 32-electron rule holds more promise. $^{51,52,71,75}$ In addition to the 18-electron and 32-electron rules, to explain the stability of main group metal atom/ion encapsulated gold clusters the 20-electron principle has also been invoked. ${ }^{76}$
The energy level diagram (Figure $2 \mathrm{~b}$ and Figure 3 ) and $\mathrm{MO}$ pictures of the encapsulated clusters (Figures 4 and 5) reveal that $\mathrm{M} @ \mathrm{~Pb}_{12}{ }^{+}$and $\mathrm{M} @ \mathrm{Sn}_{12}^{+}(\mathrm{M}=$ $\mathrm{Lr}$ and $\mathrm{Lu}$ ) systems follow the 18-electron rule with shell closing in $4 \mathrm{t}_{1 \mathrm{u}}, 3 \mathrm{~h}_{\mathrm{g}}$ and $4 \mathrm{a}_{\mathrm{g}}$ MOs corresponding to an $n s^{2} n p^{6}(n-1) d^{10}$ configuration. From Figure $2 b$ and Figure 3 it can be seen that in bare $\mathrm{Pb}_{12}{ }^{2-}$ and $\mathrm{Sn}_{12}^{2-}$ there are four valence energy level corresponding to $h_{g}, t_{1 u}, g_{u}$ and $a_{g}$ MOs. However, in metal-doped

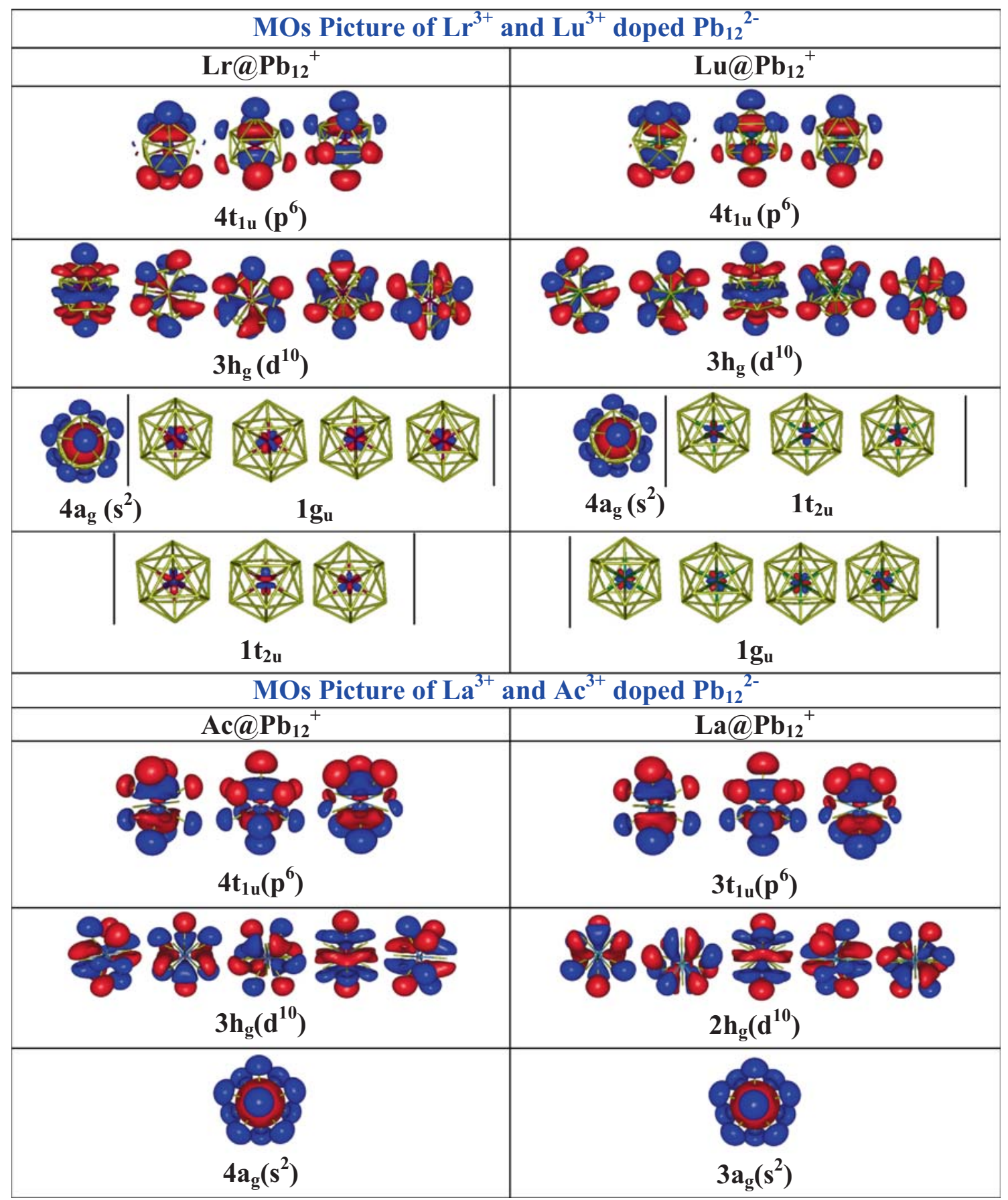

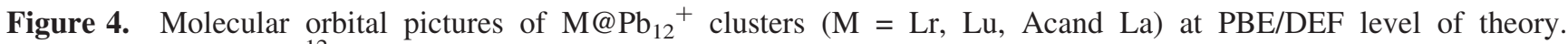
(Reproduced from Ref. ${ }^{12}$ with permission from the Royal Society of Chemistry). 


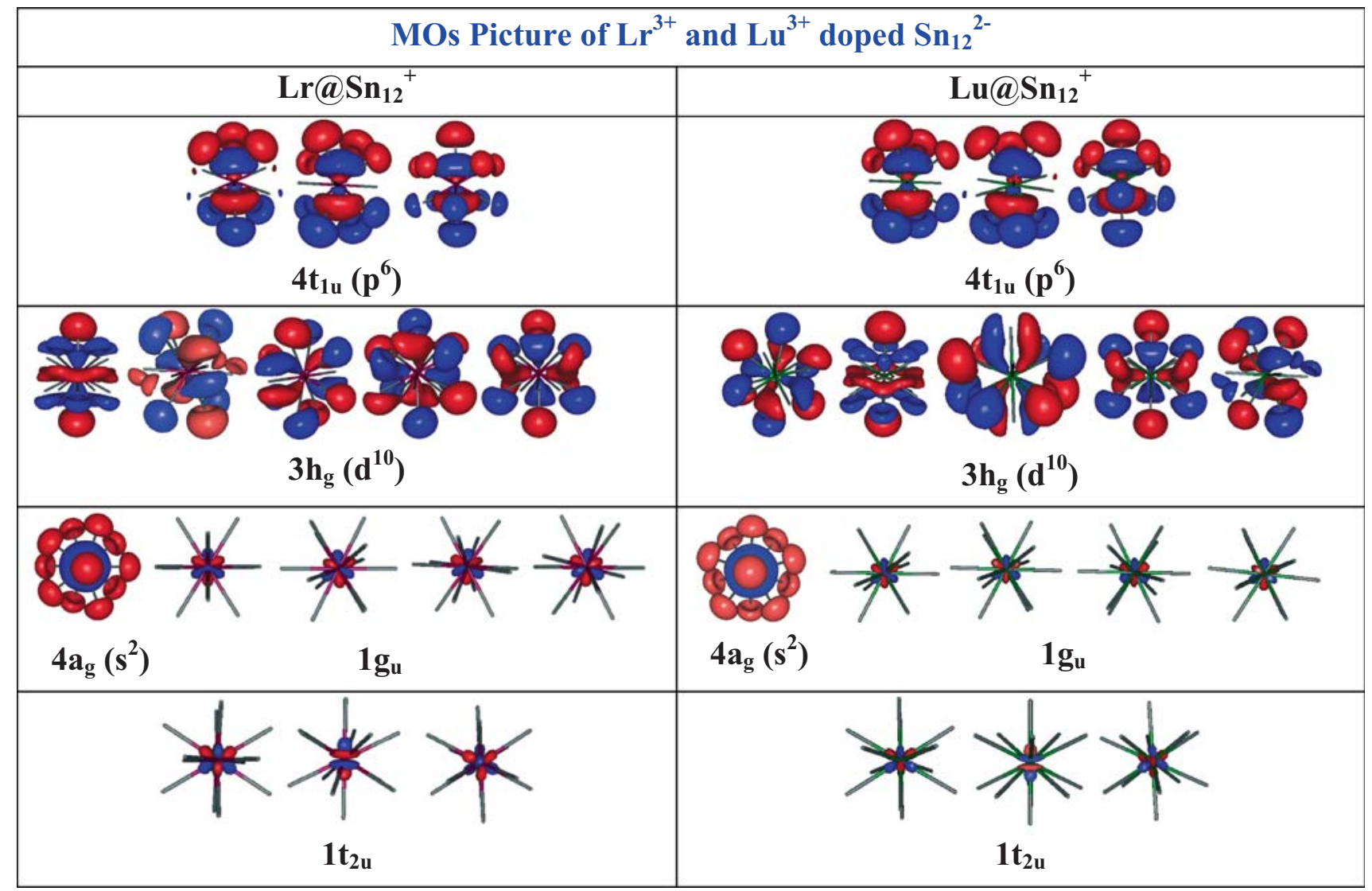

Figure 5. Molecular orbital pictures of $\mathrm{M} @ \mathrm{Sn}_{12}^{+}$clusters $(\mathrm{M}=\mathrm{Lr}$ and Lu) at PBE/DEF level of theory. (Reproduced from Ref. $^{12}$ with permission from the Royal Society of Chemistry).

clusters, apart from these energy levels one additional higher energy state corresponding to $4 \mathrm{t}_{1 \mathrm{u}}$ MOs (HOMO) is generated due to the hybridization of the doped ion with the cage atom. Therefore, the HOMOLUMO gap in the metal-doped cluster is reduced. On the other hand, early lanthanide or actinide encapsulated clusters such as $\mathrm{Pu} @ \mathrm{~Pb}_{12},{ }^{47,53}\left[\mathrm{U} @ \mathrm{Si}_{20}\right]^{6-},{ }^{6}$ $\mathrm{M} @ \mathrm{C}^{26,72}(\mathrm{M}=$ lanthanide/actinide $), \mathrm{Pu} @ \mathrm{C}_{24}{ }^{74}$ and $\mathrm{U} @ \mathrm{C}_{28}{ }^{75}$ follow the 32 -electron principle due to the participation of f-electrons in the bonding. However, in the case of $\mathrm{Lr}$ and $\mathrm{Lu}$, the $4 \mathrm{f} / 5 \mathrm{f}$ orbitals are highly shielded and their participation in the bonding with the cage atoms is negligible (Figures 4 and 5). As a consequence of the $4 \mathrm{f} / 5 \mathrm{f}$ orbital of $\mathrm{Lu} / \mathrm{Lr}$ not participating in bonding with the cage atoms, these systems follow 18-electron rule similar to that of the $\mathrm{M} @ \mathrm{~Pb}_{12}{ }^{+}$and $\mathrm{M} @ \mathrm{Sn}_{12}^{+}(\mathrm{M}=\mathrm{La}, \mathrm{Ac})$ (Figure 4).

\section{Estimation of the charge and electron localisation function}

The Voronoi charge present on the metal atoms/ions in the $\mathrm{M} @ \mathrm{~Pb}_{12}{ }^{2-}$ and $\mathrm{M} @ \mathrm{Sn}_{12}^{2-}\left(\mathrm{M}=\mathrm{Lr}^{\mathrm{n}+}\right.$ and $\mathrm{Lu}^{\mathrm{n}+} \mathrm{n}=$ $0,1,2,3)$ clusters have been studied in order to shed light on the nature of bonding within the clusters. The charges on $\mathrm{Lr}$ and the cage atom are significantly different from the initial charges on $\operatorname{Lr}(+3)$ and on the cage $(-2)$. The increase in the electron density around the encapsulated ion and a decrease in the electron density of the cage indicates that a transfer of electron density has occurred from the orbitals of the cage atoms to the central atoms. Moreover, similar charges are localised on $\mathrm{Lr}$ and $\mathrm{Lu}$, suggesting that $\mathrm{Lr}$ and $\mathrm{Lu}$ are forming similar kinds of bonds with the surrounding cage atoms.

In order to gain more understanding on the nature of the $\mathrm{M}-\mathrm{Pb}$ and $\mathrm{Pb}-\mathrm{Pb}$ bonds, the electron localization function ${ }^{77}$ (ELF) for $\mathrm{M} @ \mathrm{~Pb}_{12}{ }^{+}(\mathrm{M}=\mathrm{Lr}, \mathrm{Lu}, \mathrm{La}$ and Ac) and $\mathrm{M} @ \mathrm{Sn}_{12}^{+}$clusters $(\mathrm{M}=\mathrm{Lr}, \mathrm{Lu})$ have been obtained and corresponding ELF plots of $\mathrm{M} @ \mathrm{~Pb}_{12}{ }^{+}$ are provided in Figure $6 .^{12}$ Similar ELF plots have been found for $\mathrm{M} @ \mathrm{Sn}_{12}^{+}$clusters. ${ }^{12}$ It has been found that more localization of electrons occurs among the cage atoms than between the cage and the central metal ion. This is as expected of heteroatoms and indicates that the metal-cage bond possesses only weak covalent interaction. Further, the ELF of the M$\mathrm{Pb}$ bond is found to be larger in $\mathrm{Lu}^{3+}$ and $\mathrm{Lr}^{3+}$ encapsulated $\mathrm{Pb}_{12}{ }^{2-}$ cluster as compared to the $\mathrm{La}^{3+}$ 


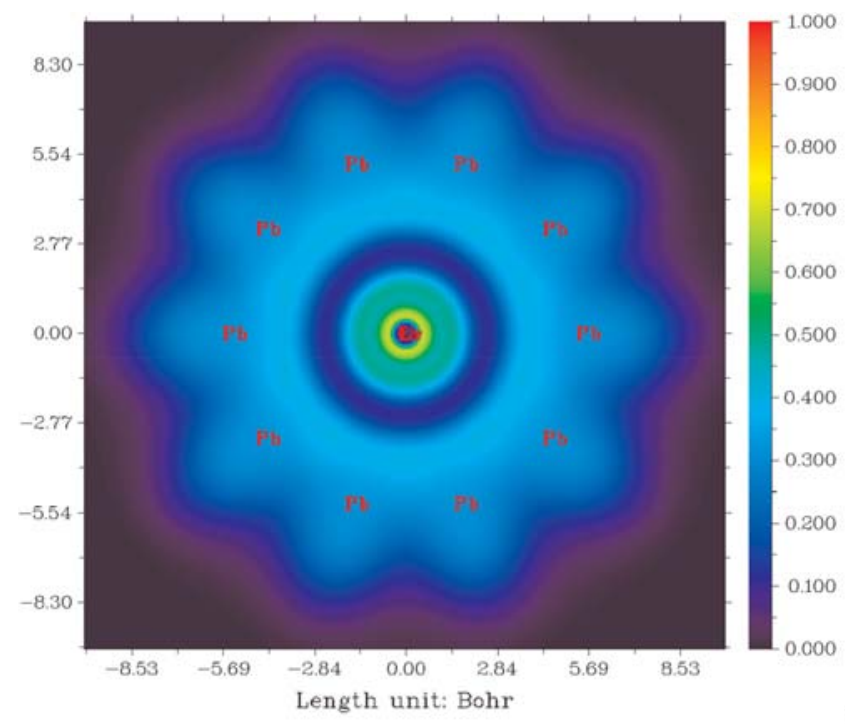

(a)
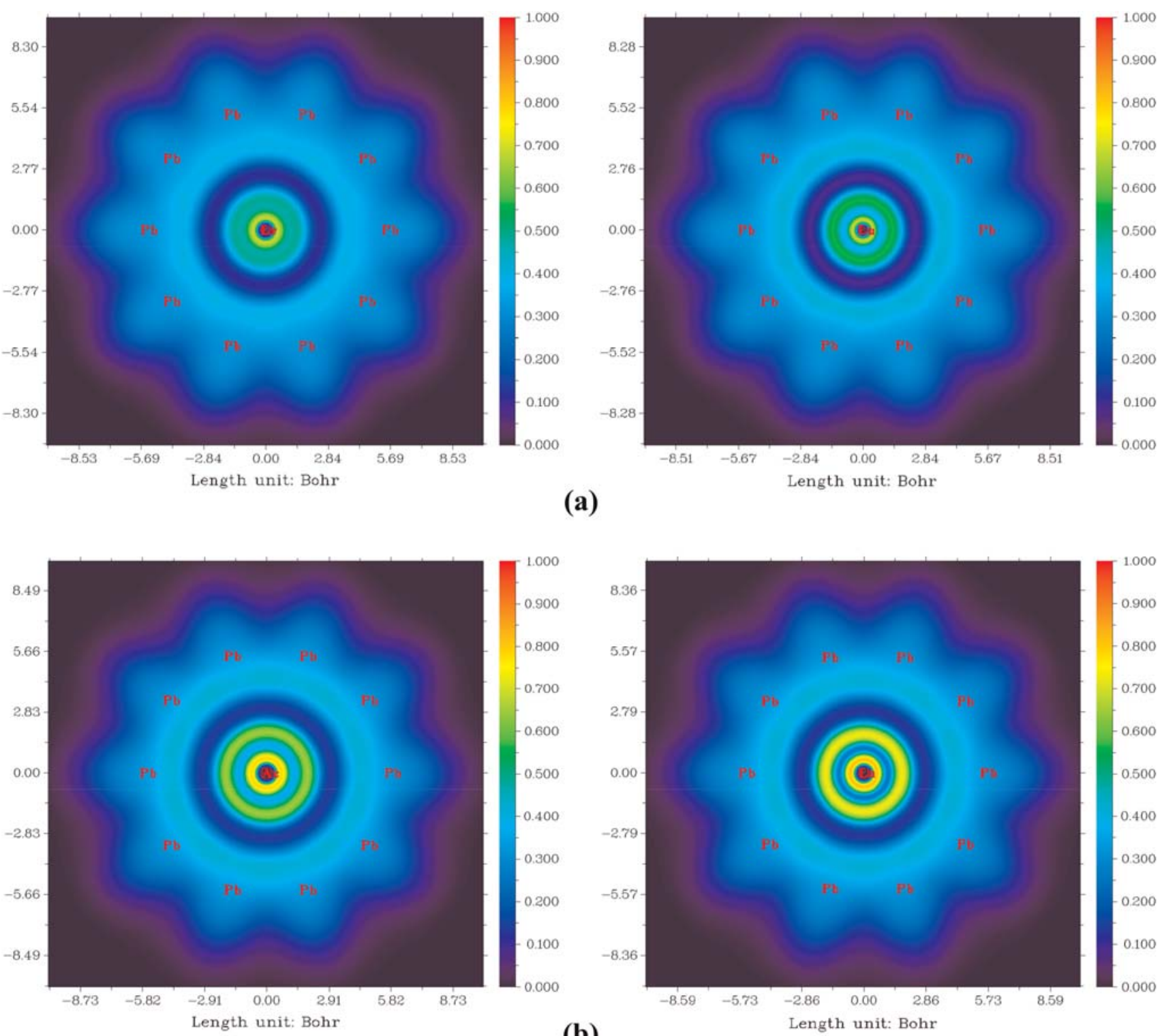

(b)

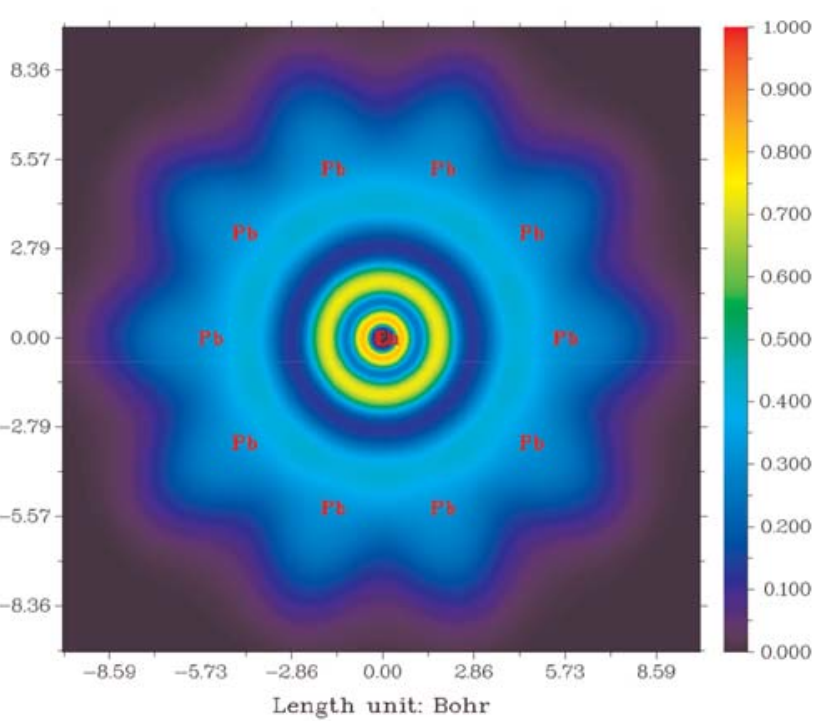

Figure 6. The 2-D colour-filled maps of the electron localization function (ELF) of (a) $\mathrm{Lr}_{0} \mathrm{~Pb}_{12}{ }^{+}$and $\mathrm{Lu}_{\mathrm{B}} @ \mathrm{~Pb}_{12}{ }^{+}$ (b) $\mathrm{Ac} @ \mathrm{~Pb}_{12}{ }^{+}$and $\mathrm{La} @ \mathrm{~Pb}_{12}{ }^{+}$, respectively. (Reproduced from Ref. ${ }^{12}$ with permission from the Royal Society of Chemistry).

and $\mathrm{Ac}^{3+}$ ion encapsulated $\mathrm{Pb}_{12}{ }^{2-}$ cluster, indicating relatively less covalent character in the $\mathrm{La}^{3+}$ and $\mathrm{Ac}^{3+}$ ion encapsulated $\mathrm{Pb}_{12}{ }^{2-}$ clusters. These observations corroborate with the trend in HOMO-LUMO energy gaps as well as those of binding energy.

\section{Conclusions}

The clusters considered in this computational study have negative values of binding energy combined with relatively large HOMO-LUMO energy gaps that indicate the stability of such encapsulated clusters. The optimized minimum energy structures and thus calculated parameters viz., electronic, thermodynamic and geometric for Lr encapsulated clusters are in a close match with those parameters corresponding to Lu encapsulated clusters. Furthermore, the similarity between $\mathrm{Lr}$ and $\mathrm{Lu}$ metal atoms are manifested in their various oxidation states, though they possess different atomic ground state valence electronic configurations. It is all the more exciting to discover that $\mathrm{La}$ and $\mathrm{Ac}$ showed striking similarities to $\mathrm{Lr}$ and $\mathrm{Lu}$ with respect to all the properties investigated and also form stable 18-electron systems. The results of our study with adequate and corroborating justifications from its different perspectives showed that $\mathrm{Lr}^{3+}, \mathrm{Lu}^{3+}, \mathrm{La}^{3+}$, and $\mathrm{Ac}^{3+}$ possess close similarities in their electronic 
as well as structural behavior, favouring the placement of all the four of these elements together into 15 element f-block rows in agreement with Pyykkö and also the convention presently followed by the IUPAC.

Although the approach adopted by us has been a comprehensive and justified one there have been further discussions on this question as appeared ${ }^{78}$ in "Chemistry World" as a news article, where Lavelle contradicted the 15-elements f-block rows. Further, Jemmis has expressed ${ }^{79}$ that placing 15 elements in each of the f-blocks is inconsistent with the 14-element upper limit of occupancy of f-block. Moreover, he also pointed out ${ }^{79}$ that many examples exist where similarities of actinides with that of the transition elements and similar behaviour of lanthanides with the main group elements are found. The periodic table as vital as it is to chemists of every kind is still a work in progress and is sure to attract more attention. ${ }^{80}$ It could well be that more super-heavy elements are waiting to be discovered and extend the periodic table beyond the $118^{\text {th }}$ element. We can, of course, continue to speculate about what could be in store for the periodic table in 150 years to come.

\section{Acknowledgements}

AC thanks SERB-DST for the post-doctoral fellowship. M.J. and T.K.G. gratefully acknowledge the liberal support provided by their host institution, Bhabha Atomic Research Centre, Mumbai. M. J. would like to thank Homi Bhabha National Institute for the PhD. fellowship in Chemical Sciences. It is a pleasure to thank Prof. E. D. Jemmis for many helpful discussions.

\section{References}

1. Jensen W B 1982 The positions of lanthanum (actinium) and lutetium (lawrencium) in the periodic table J. Chem. Educ. 59634

2. Jensen W B 2009 Misapplying the periodic law $J$. Chem. Educ. 861186

3. Desclaux J-P and Fricke B 1980 Relativistic prediction of the ground state of atomic lawrencium J. Phys. 41943

4. Brewer L 1971 Energies of the electronic configurations of the lanthanide and actinide neutral atoms $J$. Opt. Soc. Am. 611101

5. Fritzsche S, Dong C Z, Koike F and Uvarov A 2007 The low-lying level structure of atomic lawrencium ( $\mathrm{z}$ = 103): energies and absorption rates Eur. Phys. J. D. 45107

6. Lavelle L 2008 Lanthanum (La) and actinium (ac) should remain in the d-block J. Chem. Educ. 851482

7. Lavelle L 2009 Response to misapplying the periodic law J. Chem. Educ. 861187

8. Lavelle L 2008 Response to the flyleaf periodic table $J$. Chem. Educ. 851491
9. Xu W H and Pyykkö P 2016 Is the chemistry of lawrencium peculiar? Phys. Chem. Chem. Phys. 18 17351

10. Sato T K, Asai M, Borschevsky A, Stora T, Sato N, Kaneya Y, Tsukada K, Düllmann C E, Eberhardt K, Eliav E, Ichikawa S et al. 2015 Measurement of the first ionization potential of lawrencium, element 103 Nature 520209

11. IUPAC, iupac.org/what-we-do/periodic-table-ofelements/, Downloaded. (2016)

12. Joshi M, Chandrasekar A and Ghanty T K 2018 Theoretical investigation of $\mathrm{M} @ \mathrm{~Pb}_{12}{ }^{2-}$ and $\mathrm{M} @ \mathrm{Sn}_{12}^{2-}$ zintl clusters $\left(\mathrm{M}=\mathrm{Lr}^{\mathrm{n}+}, \mathrm{Lu}^{\mathrm{n}+}, \mathrm{La}^{3+}, \mathrm{Ac}^{3+}\right.$ and $\mathrm{n}=0,1,2$, 3) Phys. Chem. Chem. Phys. 2015253

13. TURBOMOLE is program package developed by the quantum chemistry group at the University of Karlsruhe, Germany, 1988: Ahlrichs R, Bär M, Häser M, Horn H and Kölmel C Chem. Phys. Lett.1989 162165

14. ADF2016; SCM, Theoretical Chemistry, VrijeUniversiteit: Amsterdam, The Netherlands. http://www.scm. com

15. teVelde G, Bickelhaupt F M, van Gisbergen S A, Fonseca Guerra C, Baerends E J, Snijders J G and Ziegler T 2001 Chemistry with ADF J. Comput. Chem. 22931

16. Perdew J P, Burke K and Ernzerhof M 1996 Generalized gradient approximation made simple Phys. Rev. Lett. 773865

17. Dolg M, Stoll H, Savin A and Preuss H 1989 Energy-adjusted pseudopotentials for the rare earth elements Theor. Chim. Acta 75173

18. Bergner A, Dolg M, Kuechle W, Stoll H and Preuss H $1993 \mathrm{Ab}$ initio energy-adjusted pseudopotentials for elements of groups 13-17 Mol. Phys. 801431

19. Dolg M, Stoll H and Preuss H 1993 A combination of quasirelativistic pseudopotential and ligand field calculations for lanthanoid compounds Theor. Chim. Acta 85441

20. Eichkorn K, Weigend F, Treutler O and Ahlrichs R 1997 Auxiliary basis sets for main row atoms and transition metals and their use to approximate coulomb potentials Theor. Chem. Acc. 97119

21. Kuechle W, Dolg M, Stoll H and Preuss H 1994 Energy-adjusted pseudopotentials for the actinides. parameter sets and test calculations for thorium and thorium monoxide J. Chem. Phys. 1007535

22. Cao X and Dolg M 2001 Valence basis sets for relativistic energy-consistent small-core lanthanide $J$. Chem. Phys. 1157348

23. Weigend F and Ahlrichs R 2005 Balanced basis sets of split valence, triple zeta valence and quadruple zeta valence quality for $\mathrm{H}$ to $\mathrm{Rn}$ : design and assessment of accuracy Phys. Chem. Chem. Phys. 73297

24. Kroto H W, Heath J R, O'Brien S C, Curl R F and Smalley R E $1985 \mathrm{C}_{60}$ : Buckminsterfullerene Nature 318162

25. Stark W J 2011 Nanoparticles in biological systems Angew. Chem., Int. Ed. 501242

26. Daniel M C and Astruc D 2004 Gold nanoparticles: assembly, supramolecular chemistry, quantum-sizerelated properties, and applications toward biology, catalysis, and nanotechnology Chem. Rev. 104293 
27. Luo Z, Castleman A W Jr and Khanna S N 2016 Reactivity of metal clusters Chem. Rev. 11614456

28. Jin R, Zeng C, Zhou M and Chen Y 2016 Atomically precise colloidal metal nanoclusters and nanoparticles: fundamentals and opportunities Chem. Rev. 11610346

29. Yadav B C and Kumar R 2016 Structure, properties and applications of fullerene Int. J. Nanotechnol. Appl. 215

30. Chen X, Deng K, Liu Y, Tang C, Yuan Y, Hu F, Wu H, Huang D, Tan W and Wang X 2008 The geometric and magnetic properties of the endohedral plumbaspherene $\mathrm{M} @ \mathrm{~Pb}_{12}$ clusters $(\mathrm{M}=\mathrm{Sc}, \mathrm{Ti}, \mathrm{V}, \mathrm{Cr}, \mathrm{Mn}, \mathrm{Fe}, \mathrm{Co}, \mathrm{Ni})$ Chem. Phys. Lett. 462275

31. Lichtenberger N, Wilson R J, Eulenstein A R, Massa W, Clérac R, Weigend F and Dehnen S 2016 Main Group metal-actinide magnetic coupling and structural response upon $\mathrm{U}^{4+}$ inclusion into $\mathrm{Bi}, \mathrm{Tl} / \mathrm{Bi}$ or $\mathrm{Pb} / \mathrm{Bi}$ cage J. Am. Chem. Soc. 1389033

32. Manzoor D and Pal S 2015 Reactivity and catalytic activity of hydrogen atom chemisorbed silver cluster $J$. Phys. Chem. A 1196162

33. Cui L-F, Huang X, Wang L-M, Zubarev D Y, Boldyrev A I, Li J and Wang L-S $2006 \mathrm{Sn}_{12}^{2-}$ : Stannaspherene $J$. Am. Chem. Soc. 1288390

34. Cui L-F, Huang X, Wang L-M, Li J and Wang L-S $2006 \mathrm{~Pb}_{12}{ }^{2-}$ : Plumbaspherene J. Phys. Chem. A 110 10169

35. Zhang $X$, Li G, Xing $X$, Zhao X, Tang Z and Gao Z 2001 Formation of binary alloy cluster anions from group-14 elements and cobalt and comparison with solid state Alloys Rapid Commun. Mass Spectrom. 15 2399

36. Bai J 2003 Synthesis of inorganic fullerene-like molecules Science $\mathbf{3 0 0} 781$

37. Esenturk E N, Fettinger J, Lam, Y-F and Eichhorn B $2004\left[\mathrm{Pt} @ \mathrm{~Pb}_{12}\right]^{2-}$ Angew. Chem., Int. Ed. 432132

38. Esenturk E N, Fettinger J and Eichhorn B 2005 The closo- $\mathrm{Pb}_{10}{ }^{2-}$ zintl ion in the $\left[\mathrm{Ni} @ \mathrm{~Pb}_{10}\right]^{2-}$ cluster Chem. Commun. 247

39. Spiekermann A, Hoffmann S D and Fässler T F 2006 The Zintl ion $\left[\mathrm{Pb}_{10}\right]^{2-}$ : A rare example of a homoatomiccloso cluster Angew. Chem., Int. Ed. 45 3459

40. Esenturk E N, Fettinger J and Eichhorn B 2006 The $\mathrm{Pb}_{12}{ }^{2-}$ and $\mathrm{Pb}_{10}{ }^{2-}$ zintl ions and the $\mathrm{M} @ \mathrm{~Pb}_{12}{ }^{2-}$ and $\mathrm{M} @ \mathrm{~Pb}_{10}{ }^{2-}$ cluster series where $\mathrm{M}=\mathrm{Ni}, \mathrm{Pd}, \mathrm{Pt} J$. Am. Chem. Soc. 1289178

41. Reveles J U and Khanna S N 2006 Electronic counting rules for the stability of metal-silicon clusters Phys. Rev. B 74035435

42. Cui L F, Huang X, Wang L M, Li J and Wang L S 2007 Endohedral stannaspherenes $\mathrm{M} @ \mathrm{Sn}_{12}^{-}$: a rich class of stable molecular cage clusters Angew. Chem., Int. Ed. 46742

43. Koyasu K, Atobe J, Furuse S and Nakajima A 2008 Anion photoelectron spectroscopy of transition metaland lanthanide metal-silicon clusters: $\operatorname{MSi}_{\mathrm{n}}^{-}(\mathrm{n}=6-20)$ J. Chem. Phys. 129214301

44. Atobe J, Koyasu K, Furuse S and Nakajima A 2012 Anion photoelectron spectroscopy of germanium and tin clusters containing a transition- or lanthanide-metal atom, $\mathrm{MGe}_{\mathrm{n}}^{-}(\mathrm{n}=8-20)$ and $\operatorname{MSn}_{\mathrm{n}}^{-}(\mathrm{n}=$
15-17) $(\mathrm{M}=\mathrm{Sc}-\mathrm{V}, \mathrm{Y}-\mathrm{Nb}$, and Lu-Ta) Phys. Chem. Chem. Phys. 149403

45. Cao T-T, Zhao L-X, Feng X-J, Lei Y-M and Luo Y-H 2009 Structural and electronic properties of $\mathrm{LuSi}_{n}(\mathrm{n}=$ 1-12) clusters: a density functional theory investigation J. Mol. Struct. TheoChem. 895148

46. Fässler T F and Hoffmann S D 2004 Endohedral zintl ions: intermetalloid clusters Angew. Chem., Int. Ed. 43 6242

47. Dognon J-P, Clavaguera C and Pyykkö P 2007 Towards a 32-electron principle: $\mathrm{Pu} @ \mathrm{~Pb}_{12}$ and related systems Angew. Chem., Int. Ed. 461427

48. Kong X-J, Ren Y-R, Long L-S, Zheng Z, Huang R-B and Zheng L-S 2007 A keplerate magnetic cluster featuring an icosidodecahedron of $\mathrm{Ni}$ (II) ions encapsulating a dodecahedron of La(III) ions J. Am. Chem. Soc. 1297016

49. Kandalam A K, Chen G and Jena P 2008 Unique magnetic coupling between Mn doped stannaspherenes $\mathrm{Mn} @ \mathrm{Sn}_{12}$ Appl. Phys. Lett. 92143109

50. Rohrmann U and Schäfer R 2015 Stren-Gerlach experiments on Fe@ $\mathrm{Sn}_{12}$ : magnetic response of a jahnteller distorted endohedrally doped molecular cage cluster J. Phys. Chem. C 11910958

51. Wang J-Q, Stegmaier S, Wahl B and Fässler T F 2010 Step-by-step synthesis of the endohedral stannaspherene $\left[\mathrm{Ir} @ \mathrm{Sn}_{12}\right]^{3-}$ via the capped cluster anion [Sn, $\operatorname{Ir}(\operatorname{cod})]^{3-}$ Chem. Eur. J. 161793

52. Rohrmann U and Schäfer R 2013 Stern-Gerlach experiments on $\mathrm{Mn} @ \mathrm{Sn}_{12}$ : identification of a paramagnetic superatom and vibrationally induced spin orientation Phys. Rev. Lett. 111133401

53. Dognon J-P, Clavaguéra C and Pyykkö P 2010 Chemical properties of the predicted 32-electron systems $\mathrm{Pu} @ \mathrm{Sn}_{12}$ and $\mathrm{Pu} @ \mathrm{~Pb}_{12}$ C. R. Chim. 13884

54. Zhou B, Krämer T, Thompson A L, McGrady J E and Goicoechea J M 2011 A highly distorted open-shell endohedral zintl cluster: $\left[\mathrm{Mn} @ \mathrm{~Pb}_{12}\right]^{3-}$ Inorg. Chem. 508028

55. Grubisic A, Wang H, Li X, Ko Y J, Kocak F S, Pederson M R, Bowen K H and Eichhorn B W 2011 Photoelectron spectroscopic and computational studies of the $\mathrm{Pt} @ \mathrm{~Pb}_{10}{ }^{1-}$ and $\mathrm{Pt} @ \mathrm{~Pb}_{12}^{1-/ 2-}$ anions Proc. Natl. Acad. Sci. U.S.A. 10814757

56. Bhattacharyya S, Nguyen T T, Haeck K, Lievens P and Janssens E 2013 Mass-selected photodissociation studies of $\mathrm{AlPb}_{\mathrm{n}}^{+}$clusters $(\mathrm{n}=7-16)$ : evidence for the extraordinary stability of $\mathrm{AlPb}_{10}{ }^{+}$and $\mathrm{AlPb}_{12}{ }^{+}$Phys. Rev. B 87054103

57. Kong X-J, Ren Y-R, Long L-S, Zheng Z, Nicol G, Huang R-B and Zheng L-S 2008 Dual shell-like magnetic clusters containing $\mathrm{Ni}^{\mathrm{II}}$ and $\mathrm{Ln}^{\mathrm{III}}(\mathrm{Ln}=\mathrm{La}$, Pr, and Nd) ions Inorg. Chem. 472728

58. Penga Q and Shen J 2008 Growth behavior of La@ $\mathrm{Si}_{\mathrm{n}}$ ( $\mathrm{n}=1-21$ ) metal-encapsulated clusters J. Chem. Phys. 128084711

59. Sekhar P, Ghosh A, Joshi M and Ghanty T K 2017 Noble gas encapsulated endohedral zintl ions $\mathrm{Ng} @ \mathrm{~Pb}_{12}{ }^{2-}$ and $\mathrm{Ng} @ \mathrm{Sn}_{12}^{2-}(\mathrm{Ng}=\mathrm{He}, \mathrm{Ne}, \mathrm{Ar}$, and $\mathrm{Kr})$ : a theoretical investigation J. Phys. Chem. C 12111932

60. Srivastava A K, Pandey S K and Misra N 2016 Encapsulation of lawrencium into $\mathrm{C}_{60}$ fullerene: Lr@C 60 versus Li@ $\mathrm{C}_{60}$ Mater. Chem. Phys. 177437 
61. Shao N, Bulusu S and Zeng X C 2008 Search for lowest-energy structure of zintldianion $\mathrm{Si}_{12}{ }^{2-}, \mathrm{Ge}_{12}^{2-}$, and $\mathrm{Sn}_{12}^{2-}$ J. Chem. Phys. 128154326

62. Li X, Kiran B, Li J, Zhai H-J and Wang L-S 2002 Experimental observation and confirmation of icosahedralW@ $\mathrm{Au}_{12}$ and Mo@ $\mathrm{Au}_{12}$ molecules Angew. Chem., Int. Ed. 414786

63. Pyykkö P and Runeberg N 2002 Icosahedral WAu $\mathrm{WA}_{12}$ :a predicted closed-shell species, stabilized by aurophilic attraction and relativity and in accord with the 18electron rule Angew. Chem., Int. Ed. 122174

64. Li L-J, Pan F-X, Li F-Y, Chen Z-F and Sun Z-M 2017 Synthesis, characterization and electronic properties of an endohedral plumbaspherene $\left[\mathrm{Au} @ \mathrm{~Pb}_{12}\right]^{3-}$ Inorg. Chem. Front. 41393

65. Langmuir I 1921 Types of valence Science 5459

66. Pyykkö P 2006 Understanding the eighteen-electron rule J. Organomet. Chem. 6914336

67. deHeer W A 1993 The physics of simple metal clusters: experimental aspects and simple models Rev. Mod. Phys. 65611

68. Luo Z and Castleman A W 2014 Special and general superatoms Acc. Chem. Res. 472931

69. Autschbach J, Hess B A, Johansson M P, Neugebauer J, Patzschke M, Pyykkö P, Reiher M and Sundholm D 2004 Properties of $\mathrm{WAu}_{12}$ Phys. Chem. Chem. Phys. 611

70. Cao G-J, Schwarz W H E and Li J 2015 An 18-electron system containing a superheavy element: theoretical studies of Sg@ $\mathrm{Au}_{12}$ Inorg. Chem. 543695

71. Dognon J P, Clavaguéra C and Pyykkö P 2009 A predicted organometallic series following a 32- electron principle: $\mathrm{An} @ \mathrm{C}_{28}\left(\mathrm{An}=\mathrm{Th}, \mathrm{Pa}^{+}, \mathrm{U}^{2+}, \mathrm{Pu}^{4+}\right)$ J. Am. Chem. Soc. 131238

72. Manna D and Ghanty T K 2012 Prediction of a new series of thermodynamically stable actinide encapsulated fullerene systems fulfilling the 32-electron principle J. Phys. Chem. C $\mathbf{1 1 6} 25630$

73. Dognon J P, Clavaguéra C and Pyykkö P 2012 A new, centered 32-electron system: the predicted [U@ $\left.\mathrm{Si}_{20}\right]^{6-}-$ like isoelectronic series Chem. Sci. 32843

74. Manna D, Sirohiwal A and Ghanty T K 2014 Pu@ $C_{24}$ : A new example satisfying the 32-electron principle $J$. Phys. Chem. C 1187211

75. Dai X, Gao Y, Jiang W, Leiab Y and Wang Z 2015 $\mathrm{U} @ \mathrm{C}_{28}$ : The electronic structure induced by the 32 electron principle Phys. Chem. Chem. Phys. 1723308

76. Muñoz-Castro A 2013 Golden endohedral main-group clusters, [E@ $\left.\mathrm{Au}_{12}\right]^{\mathrm{q}-}$ : theoretical insights into the 20-e principle J. Phys. Chem. Lett. 43363

77. Becke A D and Edgecombe K E 1990 A simple measure of electron localization in atomic and molecular systems J. Chem. Phys. 925397

78. Walshe A 2018 Chemistry World. Accessed on 21-May: https://www.chemistryworld.com/news/newrationale-for-15-element-wide-f-block/3009047.article

79. Jemmis E D 2018 Controversy continues on the position of elements in the periodic table Curr. Sci. 1142428

80. Lemonick S 2019 Rearranging the table Chem. Eng. News. 9726 